\title{
Medical Tourism Motivations: The Driving Force
}

Lakhvinder Singh

\begin{tabular}{|c|c|}
\hline & ABSTRACT \\
\hline Keywords: & Medical tourism industry has witnessed a tremendous growth in last few years especially in developing \\
\hline Medical tourism, & countries such as India, Malaysia, Singapore and Thailand. Although, there has been an increase in \\
\hline motivation, & medical tourism traffic, there is a continuous need to evaluate travel motivations among medical \\
\hline Pull, & tourists. This study highlights the driving force in the field of medical tourism which motivates medical \\
\hline Push, & tourists to travel overseas for treatment and wellbeing. The study adopts pull-push framework and \\
\hline Competitiveness & discovers that among major pull motivations are low cost, less waiting time, extensive treatment range \\
\hline & $\begin{array}{l}\mathcal{E} \text { quality care, favorable socio-cultural factors, tourists' attractions, technology and personalized } \\
\text { services. Major push forces noticed as affordability, adjournment, unavailability of specific treatment, }\end{array}$ \\
\hline & inferior health services, lack of insurance coverage, privacy concerns and legal liability associated with \\
\hline & $\begin{array}{l}\text { medical tourism. From the case study of National Capital Region (NCR) in India. The main travel } \\
\text { motivations among tourists to this region are quality E range of services, zero waiting time, eye catching }\end{array}$ \\
\hline Article History: & treatment cost, technical advancement, large pool of health professionals, facilitation, tourist attraction \\
\hline 2019 & $\begin{array}{l}\text { and language proficiency. The study recommended to develop products and services and adopt } \\
\text { appropriate marketing communication stools for the growth of medical tourism. }\end{array}$ \\
\hline ccepted:25.11.2019 & \\
\hline
\end{tabular}

Doi: https://doi.org/10.31822/jomat.621874

\section{Introduction}

People across the globe have been travelling for medical or health reasons for a long time. Since the early nineteenth century, when there were no restrictions on travel in Europe, people travelled to neighboring countries for healthcare. Hence, some researchers (Yeoman, 2008) noted that the phenomena of maintaining good health through healthy lifestyles and curative measures like medical care has been prevalent from the ancient time. Health tourism is now becoming an important economic and marketing strategy for hoteliers, resorts and tourist destinations to attract tourist visitations (Bennet, King \&Milner, 2004). Medical tourism is among the fastest growing sectors compared to the other forms of tourism.

Global medical tourism is growing to become a billion-dollar industry as people from developing countries travel to developed countries seeking for sophisticated and reliable medical treatments. However, the contemporary trend is now in the opposite direction as an increasing number of patients from developed countries travel to developing countries to receive medical treatment
(Connell, 2011). Available statistics indicate that developing countries which promote medical tourism, such as, Thailand, Singapore, Malaysia, and India have reported excellent revenue growths from previous years (Henderson, 2004; Bookman \& Bookman,2007). They also devise new strategies to attract medical tourists.

\section{Meaning and Definition of Medical Tourism}

Medical tourism is a niche market, in which people travel to other countries for obtaining healthcare services and facilities, particularly, medical, dental and surgical care. Medical tourism, which is also referred to as medical travel, health tourism or wellness tourism is a term used to describe the growing practice of travelling to other countries predominantly to seek voluntary healthcare (Pollock \& Williams, 2000; Mueller \& Kaufmann, 2001; Tontus, 2018).

Carrera and Bridges (2006) define medical tourism as the organized travel from local environment for seeking maintenance, enhancement, restoration of health including mind and body through medical care. Goodrich and Goodrich (1987) state that in 
addition to treatment, travelling for healthcare may involve consumption of tourist facilities such as hotels, transportation and visits to tourist attractions. Tourist destinations deliberately promote health-care services and facilities together with other tourism services. Therefore, there is a need to have a clear concept of medical tourism.

Cohen (2008) categorized medical tourists into five. Firstly, mere tourists who do not use any medical facility in foreign countries. The second category is tourists who use medical services due to some emergency or coincidence. The third category is medical tourists who combine both tourism and medical treatment intentionally. The fourth category is tourists who mainly come for treatment, but also enjoy vacation incidentally or during recuperative stay. The fifth category is tourists who receive treatment without using any other vacationing activities. Hence, taking into account the different typologies given above, Ackerman (2010) defined medical tourism as people who travel long distances to overseas countries to obtain medical care while simultaneously being holidaymakers, in a more conventional sense.

\section{Critical Success Factors of Medical Tourism}

In the contemporary timeframe, millions of people travel overseas for medical treatment due to various factors like cost effectiveness, better quality, less waiting time, availability of treatment, alternative therapies and natural endowments. However sufficient research efforts has been made so far (such as, Hurley, 2004;Zahra, 2007;Begde, 2008; George \& Nadelea, 2009) to portray the important elements that ensure the success of medical tourism sector. The present study noticed the following factors as major success factors in medical tourism.

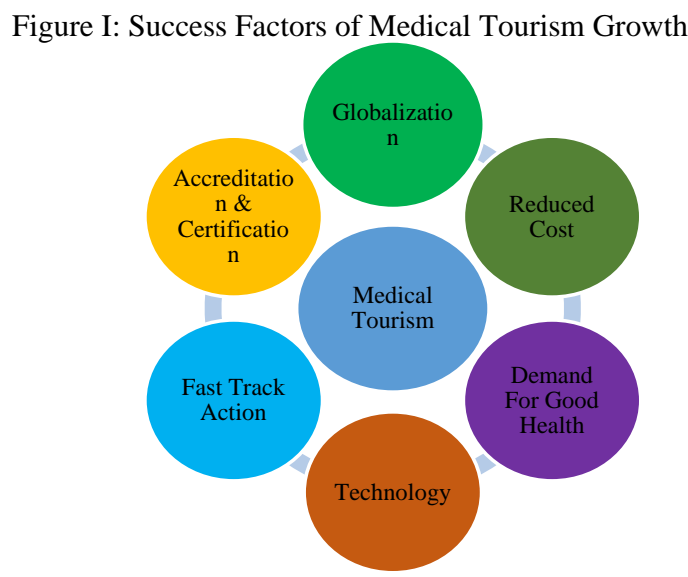

Source: Authors
The occurrences of globalization excel the growth of medical tourism as it involves facilitation of hospitalization through bilateral agreement among governments. In this case, hospitals in the host country with necessary capability and accreditation are earmarked for hospitalization from the foreign country with whom the agreement has been entered into. Moreover, hospitals directly initiate individual efforts to tie up with corporate (preferably transnational) in overseas locations. The India's Ministry of Tourism showcased that the country has huge numbers of doctors, nurses and other paramedical staff at a global level exhibition (International Tourismus-Börse) in Berlin. It also organized road shows in west Asian countries of Dubai, Riyadh, Kuwait and Doha in 2009 to promote the Indian medical tourism sector.

Healthcare costs in developing nations are extremely competitive compared to those in developed countries. With healthcare costs soaring in these countries, the relatively low cost of surgery and critical care in developing countries make it an attractive destination for medical tourism (Bookman \& Bookman,2007; Bochatons \& Letebure,2009).

In the modern industrialized world with the growth of ageing population in developed countries, the demand for good health and preventative services developed side by side. The growing demand for legacy of ethnic treatments give rise to yoga, meditation, Ayurveda, and several other ethnic treatment and rehabilitation cares all of which gradually gaining the global acceptance especially for preventative therapies.

Efficient technologies in the fields of transportation and communications systems are some of the improvements that drive medical tourism growth. Moreover, artificial intelligence techniques can provide support in many areas relevant to medical tourism. Use of the state-of-the art technologies and procedures in recognized hospitals have been heavily invested especially in supportive medical technology and operative techniques. This factor paved the way for the development of medical tourism.

Negligible waiting period, quick and immediate attention for surgeries and all interventions are another advantages which responsible for the growth of medical tourism. It is zero waiting time that attracts the worldwide medical tourists to seek treatment in countries where zero waiting time is possible for procedures such as heart surgery, kidney care, cancer treatment, 
knee/hip/joint replacements, dental, cosmetic surgeries, weight loss surgery, etc.

The recognition to health care institutions guarantee standard which enhanced patient safety, strengthened the confidence of patients, professionals, and management of health services etc. Accredited hospitals with huge capacity and gamut of specialty offerings have learned the importance of facility accreditation and accordingly provide the platform to medical tourism sector to grow.

\section{Medical Tourism Motivation- The Driving Force}

This study discusses travel motivations which spur the movement of medical tourists around the world. For this, the author uses the framework of push and pull factors which affect decision-making and travel destination choice (Prayag \& Ryan, 2011).The earlier literature indicates that the common pull motivation factors that drive people to seek treatments in other countries are accessibility (Deloitte, 2008), knowledge and awareness of the country (Horowitz \& Rosensweig, 2008), low medical cost (Jotikasthira \& Cox, 2010), and safety and security of one country (Saipraset, 2011). Christina and Katherine (2011) found pull motivation factors are lower charge, superiority of care, knowledge and status of the service provider, recognition of hospitals, travel time, ease of travel and reduced waiting periods, all of which determines the destination choice. Mohamed (2008) further noted improvement after treatments, proper care by paramedical staff, privacy and secrecy of the medical treatments as also important pull factors in medical tourism.

Ferrer and Medhekar (2012) identified the major pull factors responsible for growing medical tourism visits as low travel costs, state-of-the-art medical technology, good and affordable medical facilities, low surgical cost, joint commission internationally accredited hospitals, well-educated and groomed doctors and nurses etc. On the other hand, the main pull factors in addition to the above factors are affordable air travel and favorable exchange rates (Connell, 2006). Pradip (2011) in his research noted that India is a better option for healthcare services due to its appreciable facilities like air travel, local transportation and sightseeing, translation and escort services, comfortable hotel accommodation along with choice of not only healthcare procedures but also cuisine and hospitality.

\begin{tabular}{|c|c|}
\hline Dimension & Author \\
\hline Low cost & $\begin{array}{l}\text { Horoqitz \& Rosensweig, 2007, Chordas } \\
\text { (2009), Jotikasthira \& Cox (2010), Christina } \\
\text { \& Katherine (2011), Ferrer \& Medhekar } \\
\text { (2012), Lajevardi (2016) }\end{array}$ \\
\hline Less waiting time & $\begin{array}{l}\text { Horoqitz \& Rosensweig (2007), Christina \& } \\
\text { Katherine (2011) }\end{array}$ \\
\hline $\begin{array}{l}\text { Availability of } \\
\text { treatment }\end{array}$ & Deloitte (2008) \\
\hline Quality & $\begin{array}{l}\text { Horoqitz \& Rosensweig (2007), Mohamed } \\
\text { (2008), Chordas (2009), Christina \& Katherine } \\
\text { (2011), Lajevardi (2016) }\end{array}$ \\
\hline $\begin{array}{l}\text { Socio-cultural } \\
\text { familiarity }\end{array}$ & $\begin{array}{l}\text { Yu \& Ko (2012), Connell (2013), Lajevardi } \\
\text { (2016), Lunt, Horsfall \& Hanefeld (2016) }\end{array}$ \\
\hline Tourist attraction & Horoqitz \& Rosensweig (2007), Pradip (2011) \\
\hline Technology & $\begin{array}{l}\text { Mohamed (2008), Pradip (2011),Ferrer \& } \\
\text { Medhekar (2012), Lajevardi (2016) }\end{array}$ \\
\hline Personalization & $\begin{array}{l}\text { Connell (2006),Mohamed (2008),Christina \& } \\
\text { Katherine (2011),Pradip (2011),Ferrer } \\
\text { \&Medhekar(2012) }\end{array}$ \\
\hline
\end{tabular}

Source: Authors

Tseng (2013) found that over the past two decades the number of individuals traveling abroad for the purpose of obtaining health care (push factors) are lack of health insurance, limited coverage under health insurance, high costs of treatment and inaccessibility to different treatments in home countries. These individuals have diverse belief (pull factors) that they could obtain health care in another country that is more affordable, more accessible, and/or comparable or better quality, and doctors' and nurse's efficiency to educate their patients about their medical and healthcare goals. Helble(2011) assessed push factors for medical travel which include better transport services, long waiting lists, unavailability of treatments, poor quality of healthcare, lack of insurance coverage, cost and legal issues in home country.

Williams (2013) in a study identified push factors for medical tourists as the lack of medical services and high medical costs in their own country. Behrman (2010) also noted major push factors among medical travelers of developed countries are delayed treatment, long waiting times, high insurance costs, and unnecessary legislation which prompt patients to visit abroad for treatment. Hansen (2008) opined that the cost of insurance is too high to afford for an individual in the US as the US state regulations do not allow no-frills basic health insurance. This has prompted more Americans to opt out health insurance altogether. Chordas (2009) on the same notion elaborated that health care cost in the United States is putting pressure on some individuals to seek care overseas via medical tourism. Health plans and employers are sending patients to facilities in other areas or states for lower-cost and quality care. Incentives are being offered to employees for availing cross border healthcare services. 
Altin, Singal and Kara (2011) identified major push factors that make patients fly to foreign countries seeking healthcare and medical treatments. These are long waiting time in their home country and unavailability of proper healthcare services at their home country due to the lack of technology and equipment's. Horowitz and Rosenweig (2007) pointed out that push factors for medical travel are unavailability or restriction by legal system of a particular treatment, privacy, newly developed procedures not approved by regulatory agencies and the opportunity of an exotic vacation along with treatment. Medical tourists from northern countries often travel for a variety of reasons, including cultural or family reasons as major pull factors (Connel, 2013; Lunt, Horsfall \& Hanefeld, 2016). Yu and Ko (2012) reported that medical tourists emphasize socio-cultural factors as major push factors when selecting a destination. Lajevardi (2016) in a study noticed quality of health services, low cost of treatments, access to advanced and new medical procedures, equipment and qualified professionals and medical staff, similarity of culture and language as main pull factors in medical tourism. The study also noticed legal issues and complications as push factors for travelling abroad for medical treatment.

Table 2: Major Push Factors Identified from Review of

\begin{tabular}{ll}
\multicolumn{1}{c}{ Literature } \\
\hline Dimension & Author \\
\hline Affordability & $\begin{array}{l}\text { Connel (2006), Behrman (2010), Helble } \\
\text { (2011),Ferrer \& Medhekar (2012),Williams }\end{array}$ \\
& (2013) \\
Bdjournment & $\begin{array}{l}\text { Behrman (2010), Altin, Singal \& Kara } \\
\text { (2011), Helble (2011),Tseng (2013) }\end{array}$ \\
Unavailability & $\begin{array}{l}\text { Horowitz \& Rosenweig (2007), Helble } \\
\text { (2011),Altin, Singal \& Kara (2011),Tseng }\end{array}$ \\
& (2013) \\
Inferior health & Altin, Singal \& Kara (2011), Helble \\
service & (2011),Tseng (2013), Williams (2013) \\
Lack of insurance & Hansen (2008), Chordas (2009),Helble \\
Coverage & (2011),Tseng (2013) \\
Privacy \& & Horoqitz \& Rosensweig (2007), Mohamed \\
confidentiality & (2008) \\
Legal liability & Connell (2006), Horowitz \& Rosenweig \\
& (2007), Behrman (2010), Helble (2011), \\
& Lajevardi (2016) \\
\hline Source: Authors &
\end{tabular}

From the extensive review of earlier studies, it comes to notice that medical tourism has gained ground for a number of travel motivations' pull and push factors. Both developed and developing countries can be medical tourism destinations and have different features to leverage.

\section{Pull Factors of Medical Tourism}

The following are the pull factors identified from literature review conducted by several research studies (Saiprasert, 2011; Lertwannawit \& Gulid, 2011; Ye, Qiu \& Yuen, 2011; Gill \& Singh, 2011;
Lakhvinder Singh

Musa, Thirumoorthi \& Doshi 2012; Singh,2013). A brief overview of such pull factors has been presented in the present study also:

\section{Low Cost}

Cost is an important factor in consumer decision making for any purchase, even for essential services like healthcare. Economical and affordable pricing are the selling point of healthcare tourism. The cost differential across the world is huge. Therefore, low cost becomes an important pull factor in choosing medical tourist destination.

\section{Less Waiting Time}

The developed countries of the world are facing the problem of overburdened medical delivery systems and because of this, patients have to wait a long time for their medical treatment or procedures. This motivates them to go overseas looking for medical care services.

\section{Availability of Wide Range of Medical Treatment}

The wide range of medical services offered at a hospital is a major consideration for tourists motivated to visit another countries to seek treatment. Often the chosen hospital is perceived as more reliable and highly regarded. Therefore, extensive coverage of medical treatment can be a major pull factor in medical tourism.

\section{Quality Treatment and Care}

Use of world class implants and consumables in hospitals has gained international recognition for their state-of-art facilities and diagnostic centersby getting certification from recognized authorities like the Joint Commission for the Accreditation of Health Care Organisations (JCAHO). The quality of services is a major pull factor related to medical tourist visits (Lertwannawit, \& Gulid, 2011; Moghimehfar \& Nasr,2011; Gill \& Singh, 2011).

\section{Social and Cultural Environment}

Cultural similarity is a key motivator when health tourists select a destination. The presence of relatives or friends in visited country is a significant motivator for health tourists to visit international destinations. Perhaps being away from familiar people is a desirable choice when health tourists seek medical treatment as privacy is maintained.

\section{Availability of Tourist Attractions}

While travelling to another country for treatment, it is also possible to visit attractive places and monuments of that country. Hence, the combination of a firstclass medical treatment and a relaxing vacation while recuperating may be one 
of the main pull factors for medical travelers to visit abroad.

\section{Technology}

The advance in healthcare technology in terms of cutting-edge procedures and modern treatment methods is another important attraction to health tourists. In this instance, having techno-savvy doctors and surgeons along with supporting staff is definitely a pulling factor for health tourists.

\section{Personalized Service}

Medical tourists are motivated to use medical services of hospitals which have excellent reputation. Ease in communication is a major pull factor which attracting tourists to choose a medical tourism destination (Ye, Qiu \& Yuen, 2011; Musa, Thirumoorthi \& Doshi, 2012).A large populace of good English speaking doctors, guides and medical staff, makes it easier for foreigners to receive consultation and to discuss the mode of treatment and management.

\section{Push Factors in Medical Tourism}

Based on previous research work on identification of push factors of medical tourism (

(York, 2008; Veerasoontorn \& Rian, 2010; DeNavas, Proctor \& Smith,2011; Moghimehfar \& Nasr-Esfahani,2011). The present author also concoct an extensive review and identify the following are push travel motivation factors which influence tourists to travel abroad for health reason.

\section{Affordability}

This factor is crucial among patients who cannot afford medical or surgical treatment in their own country which is high in cost. This forces them to look for a country which offers a lower cost treatment without compromising the quality, thus they could save money. Affordability can be a major push factor which compels patients to seek medical and healthcare overseas.

\section{Adjournment}

In some nations of the world, in order to seek medical treatment, patients came across with long waiting queues in their home country, and looking for early treatment as they are not able to bear the pain. If the patient is not in a position to wait, he/she will look for alternative destinations to receive medical treatment or surgery.

\section{Unavailability}

Sometimes patients face the unavailability of some treatments, or lack of quality care in their home countries, in such case, they are ready to travel across nations. Many patients from African countries visit nearby countries where a particular procedure is not available in their home country.

\section{Inferior Healthcare Services}

The health care services in some countries are not up to the international standards such as shortage of skilled healthcare professionals, poor quality, lack of follow up care and so on. This problem pushes the citizens to visit aboard for seeking quality medical treatment.

\section{Lack of Coverage under Insurance in Home Country} Medical tourism can be alternative to the skyrocketing costs of health care, for those who required operations without insurance cover. There are some insurance plans that will cover treatment that is performed outside of home country, provided that it is not an elective procedure. For instance, developing countries are aggressively marketing to western customers and insurance agencies and advertising high quality standards with personalized service.

\section{Privacy and Confidentiality}

Another reason why people travel abroad for treatment is for privacy and confidentiality. For example, some people do not intend to reveal others about their beautification and fat reduction treatment sought by them. In this situation, it is easier for them to go on a vacation and return home with new looks. Some celebrities also prefer visiting another country for such procedures due to this reason. This phenomenon becomes the major driving force as push factors to motivate people to seek healthcare in foreign countries.

\section{Legal Liability}

There are instances when a particular diagnosis and treatment is not legally permitted in some countries such as gender change operations, baby gender determination, egg donation, sperm donation, abortions, stem cell treatment, etc. Hence in such type of circumstances, the patients have no choice but to choose another country where these treatments are permitted. Finally, as a result, the legal liability is also identified as push factors behind increasing visit of medical tourists.

\section{Case Study of National Capital Region (NCR) of India}

The present case study provides the snapshot of medical tourism and motivation of medical tourists to visit the national capital region (NCR) of India which includes New Delhi along with Gurugram, Faridabad, Ghaziabad and Noida. There are many reasons for the popularity of this region especially for being the main entry point into the country by most international patients. It has excellent 
healthcare facilities with countless numbers of world class hospitals scattered all around the city.

Major Hospitals in National Capital Region

There are sufficient number of hospitals in the region which have accreditation from different agencies such as Joint Commission International (JCI), International Standard Organization (ISO) and National Accreditation Board For Hospitals(NABH). Thestudy illustrates only JCI accredited hospitals in the region. The major hospitals selected are as followed:

Figure II: JCI Accredited Hospitals in NCR in India

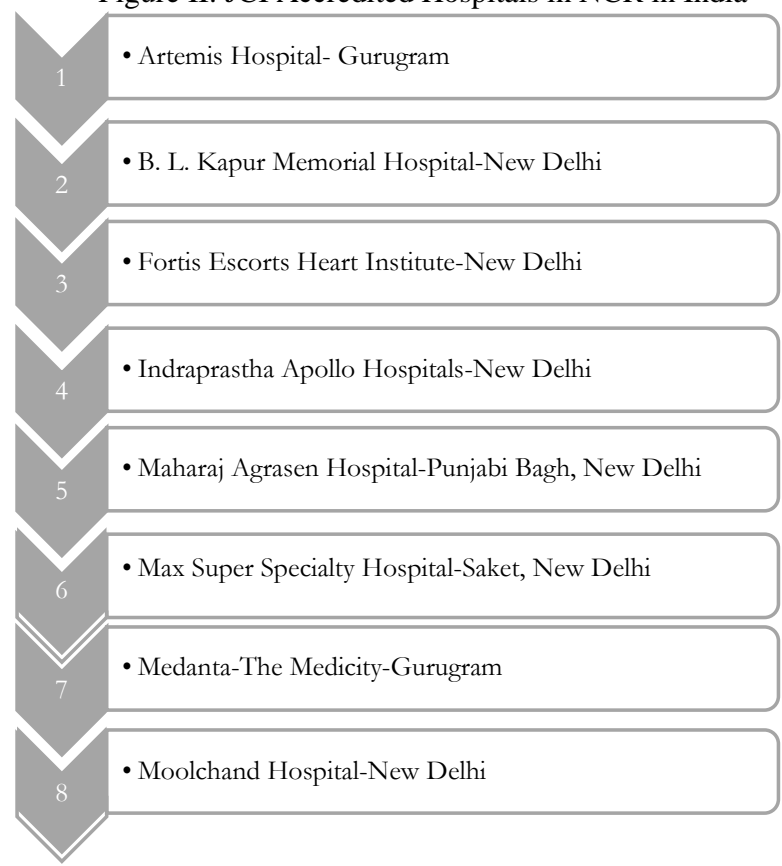

Source: Authors

- Artemis Hospital, Gurugram

Artemis Hospital is a state-of-art multi-specialty hospital located in Gurugram. This hospital is the first to achieve JCI accreditation in Gurugram area of national capital region in January, 2013. Artemis hospital has gained global recognition due to its depth of medical expertise. The main pull factors in this hospital are noticed as recognized team of doctors and surgeons, travel arrangements, visa assistance, hotel booking help and many others.

\section{BLK Super Specialty Hospital}

The BLK Super Specialty Hospital in the national capital region in located in New Delhi and it combines class and medical brilliance to render quality care and treatment for patients, both domestic and international. This hospital attains JCI accreditation in April, 2018. The important pull factors of this hospital are fully equipped operation theaters, large supply of ICU beds for different medical disciplines, $\mathrm{Wi}-\mathrm{Fi}$ enabled campus, paperless facility for healthcare, $24 \mathrm{X} 7$ blood bank, ambulance and pharmacy services for medical patients.

- Fortis Escorts Heart Institute, Okhla Road Fortis Escorts Heart Institute is one of the best cardiac care centers in the national capital region and well known for using latest and advanced technology in cardiac bypass surgery, non invasive cardiology and pediatric cardiac surgery to name a few. It has an advanced set of laboratories for nuclear medicines, hematology, radiology, biochemistry, and microbiology and travel assistance for foreign nationals. Due to excellence in healthcare services, it was accredited by JCI in February, 2010.

- Indraprastha Apollo Hospital

With over 30 years of experience under its belt, Indraprashta Apollo Hospital has become the favored destination of international patients spanning across different countries. The worldclass multi-specialty Indraprastha Apollo Hospital came into existence in 1983 and received accreditation from the JCI in June, 2005. The pull factors of this hospital are international standard healthcare, research centers for global clinical trial, legacy of excellence in healthcare, quality community services for pediatric cardiac care, and online consultation booking and payment facilities etc.

\section{- Maharaja Agrasen Hospital}

Maharaja Agrasen hospital is located Punjabi Bagh, New Delhi in the national capital region of India. Due to its excellent services in healthcare, it received the JCI accreditation in January, 2017. The major pull factors to attract medical tourists to this hospital are noted as round the clock services laboratory, accidental \& emergency critical care ambulance, with state of the art radiography technology. The hospital is also aided by a highly qualified \& experienced team of doctors \& therapists to ensure the best treatments to the patients.

- Max Super Specialty Hospital, Saket

The Max Super Specialty Hospital in Saket always strives to provide quality health care. It is located in close vicinity of the domestic airport and railway station of New Delhi. This hospital is an epitome of quality treatment, hi-tech facilities and expert doctors to serve patients. It received the JCI accreditation in February, 2017. The excellence in 
healthcare services such as green operation theatre, round the clock pharmacy and laboratory services, high class infrastructure for communication, fully equipped and hi-tech ambulance facility and comprehensive treatments available for variety of ailments are identified as pull factors of the hospital.

\section{- Medanta-The Medicity, Gurugram} Medanta - The Medicity is situated in the Gurugram area of the national capital region. This hospital has been termed as a picnic destination by many rather than a normal hospital. It is filled with everything and designated with the JCI accreditation in August, 2013. The salient pull factors of Medanta hospital are hi-tech surgical system, cyber knife robotic radio surgery system, cataract suite an image guided system, artis zeego endovascular cath lab, international patient division, robotic cardiac, urology and gynecology surgeries etc.

- Moolchand Medicity, Lajpat Nagar

Moolchand Medicity is one of the well recognized names in health care. It is a set-up that has been working right from its inception to provide international standard facilities to its patients across the national capital region. This is the India's first JCI accredited hospital which has received the accreditation in December, 2009. This hospital attracts medical travels due to its important pull factors such as specialization and excellence, easily access to surgery, top treatment facilities with the help of well trained team of doctors, surgeons, nurses and other health care providers, trustworthy services at affordable rates, comprehensive diagnostic facilities with high quality equipment available and many other facilities.

\section{Pull Factors For Tourists Visiting National Capital Region(NCR) of India}

Below are the pull factors which could attract medical tourists to the National Capital Region of India.

\section{Quality and Range of Services}

The region has hospitals with world class infrastructure that increasingly gained international recognition for the state-of-art facilities and diagnostic centers. This include quality of therapy, range of treatment options, infrastructure, skilled manpower and minimum time consuming process for medical treatment.

\section{Zero Waiting Time}

One of the greatest advantages of receiving medical treatment in the India's national capital region is the ease of getting appointments for treatment. Unlike the hospitals in developed countries where there is a long queue to wait for treatment, hospitals located in the India's national capital region now started attracting foreign patients from industrially developed countries like Britain, US and Canada.

\section{Eye Catching Treatment Cost}

Affordable pricing of medical care is the key selling point of healthcare tourism and, hence the slogan, 'first world treatment at third world prices' is applicable to the healthcare sector in the national capital region of India. This can be a crucial motivation factor for selecting healthcare in India.

\section{Technology Advancement}

The stringent quality assurance practices in the hospitals located in the India's national capital region (NCR) ensures reliable and high-quality diagnostic tests which results could be produced in timely manner to facilitate medical diagnosis and treatment plan. This advance medical technology is a crucial pull factor for the tourists to choose the region of their healthcare.

\section{Availability of Large Pool of Doctors and Supporting Staff}

The national capital region of India with sufficient man powers-doctors, nurses and paramedic - who have a high level of competency and capability in adopting new technology along with innovation and modern treatment methods. Evidently it resulted in significant increase in numbers of medical tourists who opt to receive medical treatment and surgery in the India's national capital region.

\section{Facilitation in Medical Tourism}

Government of India announced 'M-Visa' is valid for one year or the period of treatment, whichever is less. The government has also started issuing 'MX Visa' to the accompanying attendants for traveling to India including the national capital region.

\section{Tourist Attraction}

The national capital region of India is also famous for its tourist attractions including culture and heritage, monuments and landmarks such as India Gate, Qutub Minar, Red Fort, Old Fort, Jama Masjid, Jantar Mantar and the nightlife entertainment facilities in modern city of Gurugram and Noida. Hence, the availability of tourism opportunities is also a source of motivation 
among tourists to receive medical care from the India's national capital region.

\section{Language Proficiency}

Despite other driving forces, the language proficiency of the doctors, nurses and other supporting staff including travel professionals in the national capital region is also a major driving force among medical tourists to receive medical care in the India's national capital region.

\section{Conclusion}

Medical tourism is emerging and important segment of tourism industry in the contemporary world. It includes primarily the medical procedures combined with travel and tourism. The number of persons travelling to international countries for seeking healthcare and wellness treatment across the globe is increasing in last few years. Many countries such as Malaysia, Thailand, and Brazil are promoting and developing medial tourism as it can be beneficial for both the tourist generating country and host country in the form of business opportunities and infrastructure development. There are various reasons for the growth of medical tourism such as cost differences, availability, quality and less waiting time. The major motivation factors among medical tourists are low cost, better care, treatment with latest technology, services, social cultural factors, legal implications, privacy concerns etc. These motivation factors are identified as the crucial elements of medical tourism growth in India. However, some challenges such as poor institutional mechanism, improper accreditation procedure, lack of cooperation among different stakeholders, lack of uniform quality and pricing in hospitals are noticed as hindrance to the growth of medical tourism. For the successful development of medical tourism, the different stakeholders need to come out with a comprehensive policy to regulate the market to improve patient safety and outcomes, and also to prevent loss of business to other competing markets. The availability of concrete medical tourism policies provided a suitable platform to the growth of this emerging sector. The doctors, nurses and other paramedical staff members of the hospitals need to be trained regularly for adoption of new technology and recent procedures in order to provide greater and more satisfactory services to medical tourists. The management of the hospitals should take the complaints and feedbacks from patients and their companions as opportunities to improve or innovate their modus operandi. The formulation of bilateral health agreements, recognition of patients home insurers, cross border travel etc. are few key areas to look into.

\section{References}

Ackerman, S. L. (2010). Plastic Paradise: Transforming Bodies and Selves in Costa Rica's Cosmetic Surgery Tourism Industry. Medical Anthropology: Cross-Cultural Studies in Health and Illness, 29, $403-423$.

Altin, M., Singal, M. and Kara, D. (2011). Consumer decision components for medical tourism: a stakeholder approach. University of Massachusetts, 16th Graduate Students Research Conference in Hospitality and Tourism, $1-11$.

Begde, P. (2008). Opportunities and Challenges for Medical Tourism in India. Conference on Tourism in India-Challenges ahead, 15-17, May 2008, IIMK, pp. 336-356.

Behrman, S. (2010). Issues in Medical tourism: Challenges, knowledge gaps, and future directions for research and policy development. Global Journal of Health Science, 2 (2), 80-90.

Bennet, M., King, B., \& Milner, L. (2004). The health resort sector in Australia: A positioning study. Journal of Vacation Marketing, 10(2), 122-137.

Bochaton, A. and Letebure, B. (2009). The Rebirth of the Hospital - Heterotropia and Medical Tourism in Asia', Ed. Asia On Tour - Exploring the Rise of Asian Tourism, Edited by Winter, T., Teo, P. and Chang, T.C., Routledge Publishing Oxon, 97-108.

Bookman, M. Z. and Bookman, K.R. (2007). Medical Tourism in Developing Countries, Palgrave Macmillan, New York.

Carrera, P. M., \& Bridges, J. F. (2006). Globalization and healthcare: understanding health and medical tourism. Expert Review of Pharmaco economics and Outcomes Research Future Drugs, 7(1), 447454 .

Chordas, L. (2009). Heading for Home. Best's Review, $110(5), 40-44$

Christina, K. (2011). A survey of medical tourism service providers. Journal of Marketing development and competitiveness, 5(3), 117-126.

Cohen, E. (2008). Medical tourism in Thailand. $A U-G S B$ e-journal, 1(1), 24-37.

Connell, J. (2006). Medical tourism: Sea, sun, sand and surgery. Tourism Management, 276), 1093-1100.

Connell, J. (2013) Contemporary medical tourism: Conceptualization, culture and commoditization, Tourism Management, 34(1), 1-13.

Connell. J. (2011). A new inequality/Privatization, urban bias and medical tourism. Asia Pacific Viewpoint, 52(3), 11-22. 
Deloitte. (2008). Medical Tourism-Consumers in Search of Value. Deloitte Center for Health Solutions, Washington, D.C.

DeNavas, C., Proctor, B., and Smith, J. (2011). Income, Poverty, and Health Insurance Coverage in the United States: 2010, Current Population Reports, US Census Bureau.

Ferrer, M. and Medhekar, A. (2012). Key operational drivers in the medical tourism industry. International Journal of Accounting Information Science \& Leadership, 5(2), 62-76.

George, B.P. and Nadelea, (2009). Medical Tourism : An Analysis with Special Reference to its Current Practice in India, International Journal of Leisure and Tourism Marketing, 1(2), 27-35.

Gill, H. and Singh, N. (2011). Exploring the factors that affect the choice of destination for medical tourism Journal of Service Science and Management, 04 (03), 315-324.

Goodrich, J. N., and Goodrich, G. E. (1987). Health-care tourism-an exploratory study, Tourism Management, 8(3), 217-222.

Hansen, F. (2008). A revolution in healthcare, Institute of Public Affairs Review, 59(4), 42-45.

Helble, M. (2011). The movement of patients across borders: challenges and opportunities for public health. Bulletin of the World Health Organization, 89(1), 68-72.

Henderson, J.C. (2004). Health Care Tourism in South East Asia, Tourism Review International, 7(3-4), 111-121.

Horowitz M., and Rosensweig, J. (2008). Medical tourism vs. traditional international medical travel: a tale of two models. International Medical Travel Journal, 3, 30-33.

Horowitz, M., and Rosenweig, J. (2007). Medical Tourism - Health Care in the Global Economy. Physician Executive, 33(6), 24-30.

Hurley, T. (2004). Managing Customer Retention in the Health and Fitness Industry : A Case of Neglect, Irish Marketing Review, 17(1), 23-28.

Jotikasthira, N., and Cox, C. (2010). Understanding the motivations, information search needs and destination choice criteria of the medical tourist. In: 8th APacCHRIE conference: Integrating hospitality and tourism in Asia and Pacific, Phuket, Thailand.

Lajevardi,M.(2016). A Comprehensive Perspective on Medical Tourism Context and Create a Conceptual Framework, Journal of Tourism, Hospitality and Sports-An International Peerreviewed Journal, 20(1), 7-18.

Lertwannawit, A. and Gulid, N. (2011). International tourists' service quality perception and behavioral loyalty toward medical tourism in Bangkok metropolitan area, Journal of Applied Business Research, 27(6), 1-12.

Lunt, N., Horsfall, D. and Hanefeld,J.(2016). Medical tourism: A snapshot of evidence on treatment abroad. Maturitas, 88(1), 37-44.

Moghimehfar, F. and Nasr-Esfahani, M. H. (2011). Decisive factors in medical tourism destination choice: A case study of Isfahan, Iran and fertility treatments, Tourism Management, 32(6), 14311434.

Mohamed GA.(2008). Egypt's image as a tourist destination - a perspective of foreign tourists. Tourism, 3(1), 36-65.

Mueller, H. and Kaufmann, E.L. (2001). Wellness Tourism : Market Analysis of a Special Health Tourism Segment and Implications for the Hotel Industry, Journal of Vacation marketing, 7(1), 517

Musa, G. Thirumoorthi, T. and Doshi, D. (2012). Travel behavior among inbound medical tourists in Kuala Lumpur. Current Issues in Tourism, 15(6), 525-543.

Pollock, A. and Williams, P. (2000). Health Tourism Trends : Classify the Gap Between Health Care and Tourism (165-173), In W.C. Gartner and K.W. Lime (eds.). Trends in Outdoor Recreation, Leisure and Tourism, Wallingford CABI Publishing.

Pradip K. D.(2011). Marketing of Health Tourism in India. ANVESHA: A Journal of IES Management College and Research Centre, 4(1), 0974-5467.

Prayag, G., and Ryan, C. (2011). The relationship between the 'push' and 'pull' factors of a tourist destination: the role of nationality - an analytical qualitative research approach. Current Issues In Tourism, 14(2), 121-143.

Saiprasert, W. (2011). An examination of the medical tourists motivational behavior and perception: A structural model (Doctoral dissertation, Oklahoma State University).

Saiprasert, W. (2011). An examination of the medical tourists motivational behavior and perception: A structural model , (Doctoral dissertation, Oklahoma State University).

Singh, N. (2013). Exploring the factors influencing the travel motivations of US medical tourists, Current Issues in Tourism, 16(5), 436-454

Tontus, H . (2018). Promotion of Health Tourism and Evaluation of the Principles of Marketing of Health Services. Journal of Multidisciplinary Academic Tourism, 3 (1) , 67-88 . DOI: 10.31822/jomat.412322 
Tseng. H. (2013). Medical health care tourism: Why patients go overseas and what nurse practitioners need to know?.International Journal of Healthcare Management 6(2), 39-55.

Turner, L. (2007). First world health care at third world prices': globalization, bioethics and medical tourism. Bio Societies, 2(3), 303-325.

Veerasoontorn, R. and Rian, B.Z. (2010). International hospital out shopping: A staged model of push and pull factors, International Journal of Pharmaceutical and Healthcare Marketing, 4(3), 247-264.

Williams. G. (2013). Medical tourism: Becoming a standard operating procedure? Finweek, 18-19.

Ye, B., Qiu, H. and Yuen, P. (2011). Motivations and experiences of Mainland Chinese medical tourists in Hong Kong, Tourism Management, 32(5), 11251127.

Yeoman, I. (2008). Tomorrow's Tourist: Scenarios and Trends. Netherlands: Elsevier.

York, D. (2008). Medical tourism: The trend toward outsourcing medical procedures to foreign countries, Journal of Continuing Education in the Health Professions, 28(2), 99-102.

Yu, J.Y. and Ko, T.G. (2012). A cross-cultural study of perceptions of medical tourism among Chinese, Japanese and Korean tourists in Korea, Tourism Management, 33(1), 80-88.

Zahra, K. (2007). Study of Effective Factors for Attracting Medical Tourism in Iran. Master Thesis Submitted to University of Isfahan. 